\title{
EL GRUPO BRIC Y EL “EFECTO ROQUEFORT”: UNA APROXIMACIÓN A LA NOCIÓN DE REGIÓN-EMERGENTE EN EL CONTEXTO DE LA GLOBALIZACIÓN
}

Impactos derivados en la noción de ordenamiento territorial

\section{CARLOS MARIO YORY ${ }^{1}$}

\author{
Universidade Nacional da Colômbia
}

\section{Ordenamiento territorial y nuevo orden mundial: una reflexión de partida}

En un trabajo anterior (Yory, C.M. 2007) hemos planteado algunos de los retos que, a nuestra manera de ver, enfrentan hoy en día los Planes de Ordenamiento Territorial (POT), en el ámbito urbano-regional, a la luz del imperativo de movilidad que impone la globalización al mundo actual; retos que en gran medida suponen, entre otras cosas:

- Superar la noción de región natural para atender a la de región coyuntural pivotante y socio-histórica.

- Explicitar el manejo del tema de la pobreza, así como el de la inequidad social al interior de los POT y contemplar una estrategia al respecto en el entorno urbano-regional.

- Diferenciar entre sistemas estructurantes: Naturales (hidrografía, orografía, áreas de importancia recreativa y paisajística) y Artificiales (vías y transporte, centralidades, espacio público, servicios públicos); y sistemas estructurales: seguridad social y ciudadana, conectividad, saneamiento ambiental, empleo, etc.

\footnotetext{
${ }^{1}$ Arquiteto, mestre em filosofia, especialista em "Cooperación para el Desarrollo de Asentamientos Humanos en América Latina y África", doutor em Geografia Humana com pós-doutorado em Antropologia Social. Foi consultor internacional em temáticas ligadas ao planejamento, hábitat e desenvolvimento. Membro do "Grupo de Trabajo en Hábitat Popular e Inclusión Social" do CLACSO, hoje profesor na Universidade Nacional da Colombia e professor visitante em várias universidades no exterior. E-mail: alzajir@yahoo.es
} 
- Considerar el modelo de ciudad difusa al interior de las deseables relaciones de complementariedad y continuidad entre el campo y la ciudad.

- Fortalecer y posibilitar la desconcentración de funciones que normalmente generan las nuevas centralidades propuestas en los POT.

- Identificar en los procesos de negociación política el peso específico de los diferentes actores sociales.

- Incorporar el análisis del riesgo y de las oportunidades en el marco de un proyecto de seguridad urbano-regional (ciudadana, alimentaria, económica, política y ambiental).

- Establecer indicadores en materia de justicia social y derechos ciudadanos.

- Fortalecer el tema de la movilidad (particularmente derivada de factores laborales) incorporando el manejo de los impactos de la nueva movilidad y sus cambios de patrones por la vía de la desconcentración.

- Diferenciar e instrumentalizar políticas de movilidad, conectividad y transporte.

- Poner en obra el sentido de diferencia territorial en el contexto de la ciudad-región para alcanzar la competitividad global.

- Asumir las implicaciones de reconocer el hecho de que el territorio es, ante todo, una construcción social procesual auto-organizada y no simplemente una forma de ocupación espacial.

- Fortalecer el compromiso del POT con los temas del mejoramiento de la base productiva de la ciudad (y sus impactos en la movilidad) y del mejoramiento del ingreso, como precondición de equidad social y competitividad.

- Potenciar y/o crear instrumentos para el manejo de áreas metropolitanas, servicios y movilidad supramunicipal.

- Promover la concurrencia de recursos y proponer, desde aquí, un claro esquema de contrapartidas presupuestales para la adopción de corresponsabilidades multi-actorales.

- Propiciar territorialmente la integración entre capacidad empresarial, innovación e investigación, facilitando la realización de alianzas entre los sectores público y privado. 
- Considerar el establecimiento de observatorios urbano-regionales de apoyo y seguimiento a los respectivos POT y sus impactos en materia de empleo, movilidad, juventud, niñez, familia, espacio público, medio ambiente, seguridad, servicios, etcétera.

- Definir un claro esquema de alianzas estratégicas entre los sectores público y privado.

- Potenciar la generación de sub-centros sobre la estructura portante principal de las ciudades y municipios y constituir anillos y corredores de innovación que integren y articulen la ciudad-región.

- Definir una política de manejo frente a la informalidad y frente al tema de la población más vulnerable.

- Establecer indicadores de sustentabilidad, así como de gobernabilidad, productividad, habitabilidad y conectividad.

- Promover el fortalecimiento institucional (en su base territorial) por la vía de una participación deliberativa.

- Aclarar en el imaginario de ciudad cómo alcanzar la competitividad en el marco de la ciudad-región; construyendo colectivamente un correspondiente imaginario en la materia.

- Promover y propiciar la puesta en marcha de una estrategia para el fortalecimiento de la base productiva, corporativa y asociativa en la ciudad-región.

- Promover la desconcentración del empleo así como la de los equipamientos y servicios.

- Contemplar una estrategia de seguridad alimentaria así como de movilidad de carga y pasajeros.

- Fortalecer la noción de lo urbano dentro de una concepción de nueva ruralidad que permita efectuar nuevos acuerdos entre el campo y la ciudad

- Constituir instancias técnicas coordinadoras y articuladoras en la ciudad-región dentro de un sistema de centralidades potenciando nodos por niveles y manejando planos inter-escalas.

- Incorporar a los POT el diseño y constitución de un pacto multiestamentario por la constitución de un hábitat digno y sustentable. 
- Fortalecer los nodos articuladores de correspondientes redes urbanoregionales.

- Establecer una estrategia para la recualificación del recurso humano urbano-regional.

- Promover la realización de proyectos y actividades urbano-regionales integrantes y emblemáticas.

- Establecer el compromiso de los POT con las políticas de bienestar social a nivel multi-escalar para así interconectar lo municipal, lo estadual, lo regional, lo nacional y lo supra-nacional.

- Definir concertadamente con las diferentes fuerzas vivas de la sociedad los proyectos articuladores de borde pertinentes con las escalas antes mencionadas

Resaltamos que sólo hemos anotado aquí aquellos aspectos que, del trabajo antes mencionado, consideramos resultan más pertinentes con el salto de escala que de los tradicionales POT urbanos o urbano-regionales nos pueden ayudar a pensar en los retos que habría de enfrentar una planeación supra-regional o, incluso supra-nacional, enmarcada en una idea renovada de ordenamiento territorial capaz de constituir agendas internacionales concebidas en el marco de los nuevos bloques económicos que constituyen las llamadas regiones emergentes.

De este modo, con el fin de llevar la noción de ordenamiento territorial a la amplia escala que supone la globalización y sus particulares efectos sobre lo territorial en el marco de la idea de orden mundial que esta supone, consideramos necesario aproximarnos al análisis del fenómeno de reconfiguración de los nuevos espacios transnacionales que esta propone en el marco de lo que se ha dado en llamar lo grupos de países emergentes o de países con economías identificadas de tal forma.

Dentro de este marco, ya no hablamos del ordenamiento de ciudades o de regiones desde la perspectiva clásica de los Planes de Ordenamiento Territorial que buscan minimizar los desequilibrios territoriales y promover, en el mejor de los casos, un desarrollo integral (cuando no un simple crecimiento económico de dudosos réditos sociales y ambientales), sino de la manera como la lógica del capital trasnacional, a través de inducidos modelos "futurológicos", prefigura y alienta la creación de nuevos escenarios de "ordenamiento territorial", en este caso, constituyendo globalmente bloques o grupos de países con alguna o ninguna afinidad (al menos en apariencia) pero, eso sí, dispuestos a 
cualquier costo a figurar en la red de economías atractivas a la inversión y al gran capital.

Hablamos, particularmente, de las llamadas "economías emergentes" o, mejor aún, de "mercados emergentes"2 y de los nuevos grupos de países (emergentes, también) que la economía transnacional se encarga de agrupar ordenando a su arbitrio el nuevo mapa territorial de la economía mundial.

Para algunos autores, entre los que se encuentra George Magnus (2011), por país emergente se debe entender aquel que, mostrando el mayor potencial económico, resulta atractivo para la inversión; definición que, no obstante, se queda corta toda vez que, como señala Pascal Rigaud (2010), no existe una definición unificada al respecto dado que todo depende de qué se quiera enfatizar con este apelativo; en cualquier caso, para este autor, "el concepto de economía emergente se refiere a países que se caracterizan por tener, al mismo tiempo, un fuerte crecimiento de su producción y una expansión de sus mercados financieros" (Rigaud. 2010:19).

Así, adicionalmente señalaríamos que la real comprensión y uso del atributo "emergente" en cada caso debe considerar aspectos como el incremento de la producción; el modelo económico empleado; la asertividad de las políticas económicas, así como su continuidad y sustentabilidad; los resultados de una óptima adecuación a las exigencias internacionales frente al ajuste estructural (sin entrar a analizar en este punto sus consecuencias frente a temas como la seguridad social o la equidistribución de los excedentes); la capacidad de endeudamiento y/o de pago; la potencialidad de sus recursos naturales o humanos; los incentivos tributarios o arancelarios para la inversión; la estabilidad económica y política; el liderazgo regional; las alianzas estratégicas establecidas con otros países; en fin, toda una serie de condiciones o circunstancias que, de tal suerte, entrarían a calificar la naturaleza de la emergencia.

${ }^{2}$ El concepto de mercado emergente fue propuesto en 1981 por Antoine van Agtmael economista del Banco Mundial para aludir de una manera sutil a los llamados países en subdesarrollo o, si se prefiere, en vías de desarrollo. (Ampliar en The Economist. September 18th, 2008. "Ins and Outs. Acronyms BRIC out all over", disponible en http://www.economist. com/node/12080703?story_id=12080703) 


\section{EI Grupo BRIC y el "efecto Roquefort": un caso emblemático de "ordenamiento territorial" derivado de la noción de región- emergente}

De acuerdo con lo señalado, nuestra preocupación en este punto se concentra en examinar la manera como se ordena el territorio de la economía mundial en el marco de los llamados países emergentes; esto con el fin de entender que lo que ocurre en la escala urbana y regional a la que veníamos haciendo alusión, es directa consecuencia del modelo económico que de hecho se viene aplicando a nivel global; modelo desde el cual el ordenamiento, valga decir, el pleno control de la economía, es un asunto que necesariamente pasa por el control de los territorios, cualquiera que sea su escala; de ahí la conveniencia de agrupar, integrar, asociar o, todo lo contrario, de disolver, confrontar o enfrentar unos con otros con tal de no perder los hilos que rigen los destinos del globo; al fin y al cabo planear es controlar y si se planifica evidentemente es para ello ¿Qué es si no la planeación, un eficaz instrumento de tecnología política?

Surgen así, de la noche a la mañana, grupos enteros de países, no necesariamente vecinos, integrados bajo la impronta de marca que en el lenguaje de la mercadotecnia proporcionan las siglas y los acrónimos del tipo BRIC, N-11, G-6, CAIRNS, CIVETS, EAGLE, MIST, etcétera.

De este modo, traspasar la idea clásica de región-vecinal da cuenta de la aparición de una particular forma de agrupación territorial transfronteriza o, meior, trans-continental (aún no podemos llamar asociación o, mucho menos, comunidad) promovida por el mercado y por las decisiones del gran capital.; agrupación que, por acusar una cierta forma de porosidad espacial fluida y permisiva al interior de un todo pre-existente (en este caso el mundo) hemos querido bautizar metafóricamente con el título de "efecto Roquefort".

En este contexto, el "gusano" que libremente circula por el interior del queso devorándolo y asomándose libremente por uno u otro orificio de su superficie lisa ${ }^{3}$ - la cual conecta de maneras imprevistas, tal como se

${ }^{3}$ En realidad sabemos que los orificios en el queso no son producidos por un gusano
devorador que de tal forma se abre paso dentro de éste, sino por los gases que generan las
baterías empleadas en su producción; no obstante, para efectos de ilustrar nuestra
metáfora en el contexto aludido, preferimos conscientemente adoptar la respuesta infantil
a la razón por la cual cierta clase de quesos presentan agujeros. Sobre esta base, apelamos
a la indulgencia del lector ilustrado para que se entienda de una manera más sugerente que 
conecta la superficie del planeta "alisada" por la desregulación impuesta por el mercado en el ámbito de la globalización neoliberal - no es otra cosa que el capital trasnacional.

De esta suerte, el "efecto Roquefort" hace trascender, en mucho, las fronteras ideológicas, culturales, sociales o políticas de los distintos territorios unificando o, al menos, conectando, contextos en todo disímiles a la luz de una lógica asociativa, mercantilista y empresarial que va no requiere compartir fronteras como en otro tiempo hiciera la Comunidad Europea, la frustrada Comunidad Andina de Naciones o el inestable y volátil proyecto del Mercosur.

A este respecto, mucho se ha dicho del grupo BRIC (hoy en día diríamos, de la marca BRIC), conformado inicialmente por Brasil, Rusia, India y China, acrónimo que, a raíz del 11-S y su contundente manera de evidenciar el debilitamiento de las grandes potencias mundiales, propone Jim O'Neill en 2001, economista y alto eiecutivo del Banco estadounidense Goldman Sachs, para aludir a un privilegiado grupo de países emergentes (valga decir, no desarrollados pero con posibilidades de llegar a serlo) que, como aguieros en un queso abierto desde dentro por las dinámicas del gran capital, constituyen lo que llamaríamos un nuevo ámbito regional hecho, ya no de contigüidades, sino de coyunturas políticas y económicas.

Sobre esta base, los países mencionados (iunto con el recién incorporado Sudáfrica), como en 1984 lo hicieron Argentina, India, México, Tanzania, Suecia y Grecia, a través del Grupo de los seis (G-6), creado con el fin de manifestarse en torno a los riesgos de la carrera armamentista o, en 1986, Argentina, Australia, Bolivia, Brasil, Canadá, Chile, Colombia, Costa Rica, Filipinas, Guatemala, Indonesia, Malasia, Nueva Zelanda, Pakistán, Paraguay, Perú, Sudáfrica, Tailandia y Uruguay, a través del Grupo CAIRNS (1986) conformado con la idea de liberalizar el comercio internacional de productos agro-alimentarios; ilustra, nuevamente, la necesidad de la integración transnacional.

De esta suerte, y quizá adoptando la misma lógica, se anticipa la creación de nuevos grupos por parte, siempre, de instancias financieras que en poco tienen en cuenta una lógica distinta a la de la movilidad estratégica

irreverente el tratar de explicar uno de los aspectos más complejos de la economía política de la globalización a partir de una metáfora tomada de la imaginación infantil. 
del capital v que, por tanto, no suelen atender ningún tipo de variable que no sea estrictamente economicista.

Así, por eiemplo, Goldman Sachs, el mismo Banco artífice de la marca BRIC, en 2005 lanza la idea del N-11 (Next -11) agrupando a Bangladesh, Corea del Sur, Egipto, Filipinas, Indonesia, Irán, México, Nigeria, Pakistán. Turquía y Vietnam, aduciendo que muy seguramente estos países seguirán los pasos del BRIC.

De igual forma, el Banco HSBC y The Ecomist Intelligence Unit proponen, en 2010, la creación del Grupo CIVETS compuesto por Colombia, Indonesia, Vietnam, Egipto, Turquía y Sudáfrica, iustificando su creación en el hecho de que estos países cuentan, en opinión de los promotores del Grupo, con estabilidad política, demografía considerable y ioven, y economías diversas y dinámicas; no sobra recordar aquí que esta clasificación es anterior al conflicto socio-político que culminó en Egipto con la caída del régimen de Mubarak.

De otra parte, está también el denominado $\mathrm{y}$, a nuestra manera de ver, excesivamente optimista "Club del 7\%", propuesto por Standard Chartered en 2010, en el cual se incluven China, India, Camboya, Azerbaiyán, Turkmenistán, Kazaistán, Tavikistán, Etiopía, Uganda, Chad, Mozambique, Angola, Sudán, Sierra Leona y Ruanda. Países que si bien han demostrado un crecimiento relativamente sostenido superior a la cota del $7 \%$ no son garantes, al menos aún, de estabilidad socio-política y, por lo mismo, económica.

Lo que llama la atención en este caso, es la proyección que se hace de países con enormes disparidades, no sólo entre sí, como China y Ruanda, sino al interior de ellos mismos, como los países africanos mencionados. lo cual resulta ser. en cualquier caso, una bomba de tiempo en lo que respecta a lo que la economía podría llamar un futuro alentador.

En este orden de ideas aparece el Grupo EAGLE (Emerging and Growth-Leading Economies), propuesto por el Banco BBVA, también en 2010, donde, partiendo del Grupo BRIC suman México, Turquía, Indonesia, Corea del Sur, Egipto y Taiwan en función de la demanda creciente de su población.

Tenemos también al llamado Grupo de los Seis Grandes, propuesto por Accenture en 2010, para sumarle al BRIC. México y Corea del Sur, aduciendo que responden a economías capaces de reconfigurar el mapa de operación de las grandes empresas transnacionales. 
Finalmente, está el Grupo MIST, recientemente propuesto por el citado Goldman Sachs (2011), el cual estaría conformado por México, Indonesia, Corea del Sur y Taiwan; países que en opinión de este prestigioso Banco. contarían en treinta años con las condiciones que hoy en día ofrece el BRIC.

Como se ve, México, Indonesia y Corea del Sur, que aparecen en cuatro registros de los Grupos anteriores, seguidos de Turquía y Egipto, que aparecen en tres, parecen ser los países del siguiente renglón en lo que se refiere a provección de su economía; de hecho, llama la atención que sobre todo México y Corea del Sur no figuren ya, de hecho, en el famoso BRIC y que sí lo haga Sudáfrica, país que aún no ha demostrado las dotes altamente comerciales de los dos países anteriores; del mismo modo, llama la atención la débil alusión a India dentro de los Grupos mencionados, ya que apenas aparece con un registro por fuera del BRIC al que pertenece.

En cuanto a la exclusión de México y de Corea del Sur de este exclusivo "club", la explicación simplista, aunque insuficiente y poco creíble suele remitirse al hecho de que ambos países pertenecen a la OCDE, no obstante creemos que existen meiores y más convincentes razones, sobre todo en el caso de México, para explicar dicha exclusión.

En este sentido, se podría decir que la tradicional "ventaja" mexicana, derivada de la vecindad de los Estados Unidos, hoy en día es su principal problema dado que la excesiva dependencia de sus mercados respecto de este país de seguro es un factor que pesa a la hora de estructurar posibles alianzas con otros países pues como señala María Cristina Rosas (2011) la posibilidad de que México lleve a cabo un trabaio coordinado con otros países "resulta obstaculizada por la preeminencia de Estados Unidos en sus relaciones económicas internacionales" (Rosas. 2011:37); situación agravada por el hecho de que, excepción hecha de China, los demás países con los que se agrupa en las organizaciones mencionadas, a la fecha muy poca relevancia tienen en su actual política comercial.

La situación es clara para la economía mexicana: o se abre al mundo o se hunde con el barco norteamericano en medio de la flagrante crisis económica que lo acompaña. En este contexto, la aludida "ventaia" mexicana derivada de la cercanía y estrecha dependencia de los Estados Unidos que fungió como oportunidad durante todo el desarrollo de su vida independiente, resulta hoy en día ser un problema estructural en el marco del evanescente mapa de la economía mundial. 


\section{Emergencia económica y grupos territoriales emergentes}

La verdad, es que el origen de los llamados grupos territoriales emergentes es necesario buscarlo en las motivaciones de los Bancos y de las entidades financieras que, en el contexto de la crisis económica actual, derivada de la propia crisis del modelo económico capitalista neoliberal, no sólo los inventan, tratando de reciclar y salvar el modelo, sino que los promueven - a través de novedosas estrategias de marketing - asignándoles el ostentoso título de "economías del futuro".

De otra parte, es claro que esta motivación, no sólo recoge la incertidumbre $\mathrm{y}$, a la vez, la desconfianza que en el marco de la crisis económica vigente se tiene frente a las grandes potencias, particularmente hacia los Estados Unidos ${ }^{4}$, sino que, en consecuencia, crea nuevos productos para la inversión presionados por las grandes empresas.

${ }^{4}$ En El mundo después de USA, Fareed Zakaria (2009) realiza un lúcido análisis en el que plantea la importancia de evaluar las condiciones de ascenso de nuevas economías coloca como ejemplo a Brasil así como a Rusia y a China - antes de preocuparse por tratar de entender al colapso norteamericano. Su sospecha radica en la manera programada y, por lo mismo, nada inocente, como han ido fungiendo estas economías de la mano de los propios intereses que les han dado el estatus que hoy en día ostentan y que con gusto aceptan en el marco de efectivas y claras conveniencia; al fin y al cabo, designar supone organizar, ordenar y, por lo mismo, legitimar. Lo que llama la atención es la gran responsabilidad con la que se carga a estos países en quienes se empiezan a centrar buena parte de las expectativas, como si tuvieran la posibilidad de sacar al mundo de la crisis de espaldas a su propia realidad; una realidad en la cual resaltan, como común denominador, las disparidades sociales, la inequidad, los desequilibrios territoriales y, sobre todo, la pobreza. Así preguntaríamos ¿En verdad son estos los países que van a sacar al mundo de la crisis? ¿Corresponderá a Beijing, Moscú, Nueva Delhi y Brasilia tomar las decisiones o, más bien, serán los nuevos títeres del sistema financiero internacional? Como en el crack de 1929, el lugar de la fractura económica fueron los Estados Unidos, solo que en ese entonces correspondió a los llamados países desarrollados enfrentar la situación. ¿A cuenta de qué y con qué, lo van a hacer ahora los países del "Tercer Mundo" en el marco de una agenda interna que aún no han logrado resolver? 
El principio es simple, constituir nuevas oportunidades de negocio y alentar la inversión en aquellos países y empresas con una nula o escasa presencia en las grandes bolsas mundiales, para lo cual los Corporativos del tipo Goldman Sachs crearon nuevos fondos. La prioridad, en este caso, se la llevaron Brasil, Rusia, India y China pero, como hemos visto, existe una larga lista, no sólo de países, sino de Grupos por constituir v avalar con fondos de capital, acciones u otras formas de inversión directa o indirecta.

Asistimos así a la creación de Grupos sin Agenda pues gracias al "efecto Roquefort" del cual hablamos ésta ya no es necesaria, basta con que los países llamados asomen la cabeza por el intersticio que la lógica del capital les ofrezca baio el incentivo de hacer parte de las llamadas "regiones ganadoras"; al fin y al cabo, se trata de ganar notoriedad so pena de ser considerados irrelevantes o, peor aún, prescindibles.

No es gratuita la manera como la estrategia de marketing que acompaña la promoción internacional de tales Grupos, en el marco de un dudoso halo de prosperidad, estabilidad y rentabilidad con que se quiere "vender" la imagen de los países elegidos dentro de los mismos (particularmente dentro del BRIC), ligada a una política de meiora de su propia imagen, ha logrado diluir, al menos en parte, los estigmas particulares que tradicionalmente los han acompañado: el atropello sistemático a los derechos humanos en China; las atávicas formas de exclusión social y de esclavitud que acompaña el sistema de "castas" en la India: la elevada tasa de homicidios v los enormes desequilibrios sociales en Brasil; o la mafia y la corrupción en Rusia.

Situaciones que en poco, o en nada, afectan las decisiones de los inversionistas entusiasmados por el apoyo denodado que les brindan los Bancos para invertir en aquellos países. Otra cosa sería que cada país se atreviera a contar, a provectar y a enfrentar su propia historia, actuando desde ella (tanto hacia adentro como hacia fuera) y no la que publicita la lógica del capital transnacional ofreciendo en el mercado una imagen dulcificada de la misma para atraer, tanto turistas, como inversión.

El hecho es que, en el contexto de la economía de mercado en que nos encontramos, los países tienden a mostrarse, "etiquetándose", no como son, sino como quisieran ser a la luz del concepto marca-país, de suerte tal que la "denominación de origen" con que quieren auto-proyectarse 
requiere disfrazar sus miserias, desigualdades, discriminaciones e inequidades ubicado su horizonte de sentido para la inversión bajo el optimista pero, también, un tanto desesperado imperativo del "ahora".

No obstante, en el caso de los países BRIC hablamos del 2050 como horizonte de sentido para "asumir el liderazgo de la economía mundial", mientras tanto, no resultan claros los beneficios de pertenecer a este exclusivo "club", particularmente en la manera como tal adscripción beneficiará a la mavor parte de su población. sobre todo en los casos de India y Brasil donde las diferencias e inequidades son más acentuadas.

Después de todo, no podemos desconocer el hecho de que el crecimiento económico no va necesariamente de la mano de un proceso de desarrollo territorial, toda vez que éste, al menos en los países en vías de desarrollo, logra meiorar sus tasas de crecimiento a costa de la plusvalía obtenida de la fuerza de trabajo; es decir, de los trabajadores; esto porque tales países cuentan con menos capital por trabajador que las economías desarrolladas, lo que hace que las ganancias del capital sean mayores pero que el crecimiento del PIB no de cuenta, en modo alguno, de la anhelada, aunque dudosa mejora en la calidad de vida de los habitantes.

En este contexto, y a la luz de la crisis generalizada en que nos encontramos, el asunto no puede seguir concentrándose en el crecimiento y la acumulación per se, sino en la distribución y en la justicia social, para lo cual el Indice de Calidad de Vida (ICV) debe ser el indicador a tener en cuenta más allá de los inocuos datos que para medir los derroteros antes mencionados proporciona el PIB; de ahí que las decisiones no deban quedar en manos del mercado, sino en la de las políticas de estos países, razón de más para que las directrices de Grupos como el BRIC no las establezcan los Bancos sino las agendas de cada uno de los países involucrados y la constitución de una agenda común entre todos ellos.

A fin de cuentas, las estrategias de planeación y desarrollo de los distintos países son un asunto que debe recaer sobre ellos mismos en el marco de un horizonte de sentido concertado con sus habitantes y apoyado con las herramientas gobernativas, jurídicas e institucionales pertinentes.

Así, la modificación en la noción tradicional de región que explica el "efecto Roquefort", precisamente da cuenta de que, a través de éste, va no hacen falta agendas, causas o motivaciones particulares (frenar la carrera armamentista, exigir la condonación de la deuda externa, crear un fondo común para el cuidado del medio ambiente o, entre otros, garantizar el comercio justo, particularmente agro-alimentario) sino atender, de 
manera exclusiva, a la lógica del capital con el fin de posicionar a los países miembros como los nuevos "motores" de la economía mundial.

Desde esta perspectiva los BRIC, en realidad, no se puede decir que constituyan una agrupación en cuanto tal (no todavía) - he ahí parte de la emergencia de su emergencia - no obstante, por compartir un cierto sentido de oportunidad, anticipada por los altos eiecutivos del Goldman Sachs, se están empezando a reunir, quizá con el fin de tratar de aclarar, entre sí, qué fue lo que vieron en ellos los economistas londinenses y cómo pueden capitalizar cada uno y, a lo meior, en conjunto, la vitrina mediática que hasta ahora se les ha proporcionado, a pesar de que, por ahora, son muchas más las cosas que los separan que aquellas que los unen, razón más que de peso para establecer $\mathrm{y} / \mathrm{o}$ fortalecer sus alianzas transversales antes de lanzarse al mundo como un, hasta ahora, dudoso bloque económico.

De otra parte, el hecho de que aún los BRIC no tengan una agenda se debe, no sólo a lo reciente de su existencia, la que, por cierto, ninguno de sus miembros pidió, sino al hecho de que aunque sus economías podrían complementarse, la verdad es que en la práctica son rivales y no poseen una interdependencia que de manera efectiva los haga aliados estratégicos; de hecho, China e India son rivales, no sólo en mano de obra barata sino en tecnología. así como. por otro lado. lo es China frente a Rusia: valga decir que es difícil imaginar un país para el cual China no sea un competidor.

Sobre esta base, y ante una ausencia de agenda común, bueno es hablar de relaciones binacionales o de acuerdos internos entre algunos de ellos; para el efecto las reuniones que los países miembros del BRIC han venido llevando a cabo anualmente desde 2009 donde se debaten los grandes temas mundiales $\mathrm{y}$ donde, si bien empiezan a haber pronunciamientos comunes. estos no pasan de la denuncia y no logran establecer compromisos ni particulares ni vinculantes.

Entre estos pronunciamientos, como señala Rosas (2011), cabe destacar el de la necesidad de constituir un orden internacional multilateral y no único y hegemónico como el que insiste en tratar de imponer los Estados Unidos, y el de proponer la creación de un sistema más abierto y justo en lo que tiene que ver con el maneio de los productos agrícolas. Proponen, además, la apertura del sistema financiero y su decidida regulación a través de una instancia internacional; en este marco se aboga por la creación de un nuevo sistema de divisas aieno tanto al dólar como al euro y la creación de instancias supra-nacionales que garanticen la democratización internacional y equitativa en las tomas de decisión. 
Con todo iPodemos afirmar que el BRIC será el nuevo motor de la economía mundial? Dudoso, pues al fin y al cabo, no olvidemos que son los países importadores y no los exportadores los que resultan ser los verdaderos motores de la economía, pues tal como señala Hinds (2011): "los motores son los compradores netos, los que importan más de lo que exportan, no los vendedores netos. Los primeros generan demanda insatisfecha en los mercados internacionales; los segundos la llenan" (Hinds, 2011).

En este contexto, Brasil e India, a diferencia de China, compran más de lo que venden, lo cual, aunque sea en cantidades pequeñas comparadas con el resto de los grandes consumidores (Estados Unidos. España, Italia, Grecia, Inglaterra, Francia, Australia y Turquía, según datos de Hinds. 2011), coloca a los primeros en la autopista de una particular clase de competitividad: la de la compra y no la de la venta, de tal suerte que la pugna por quién habrá de liderar el BRIC está dada en una franca competencia por dinamizar la economía, es decir, por convertirse en el motor de los motores comprando más.... Quién será el abanderado, dentro de los países miembros, capaz de asumir tal tipo de riesgo? Es decir, de pagar el precio por comprar más que los demás, muy seguramente endeudándose de manera proporcional al tamaño de su ambición (ya hemos visto lo que a este respecto ha pasado con los Estados Unidos).

Valga señalar que a esta carrera se van sumando, dentro y fuera del BRIC, y con mayor peso que India y Brasil, países como China, Alemania, Japón, Arabia Saudí, Rusia y Noruega, lo cual, al deiar por fuera a los dos países antes mencionados (Brasil e India), pone en evidencia las disparidades y asimetrías al interior del Grupo. Aquí Rusia y China, sobre todo este último, empieza a encontrar un equilibrio entre lo que compra $\mathrm{y}$ lo que vende pues entre más vende productos manufacturados, más tiene que comprar materia prima: la que, de antemano, va tiene garantizada un amplio nicho en el mercado avalado con la amenazante marca made in China: país que, desde la perspectiva del presente análisis, le competería la función de asumir el liderazgo.

Sin los países compradores, los vendedores no tendrían razón de ser $\mathrm{y}$, en consecuencia, no podrían vender más de lo que compran; no sobra recordar que antes de la crisis el más grande de los motores v, por tanto, el más grande comprador. era los Estados Unidos quien consumía el $40 \%$ de la demanda neta en los mercados internacionales 


\section{El papel de los "motores económicos" en la actual crisis económica mundial: una aproximación desde la noción de integración regional}

En el contexto señalado vale la pena preguntarnos i.Qué tan ventaioso es ser "motor"? habría que preguntarle a Estados Unidos, España, Italia o Grecia pues entre más se compra sin que hava un equilibrio con la venta más crece la deuda $\mathrm{y}$, por tanto, la crisis; como claramente han acusado estas economías particularmente en los tres últimos años.

Así, como ocurrió en el caso de los Estados Unidos, al disminuir sus importaciones bajaron las exportaciones de China, su mavor proveedor, lo cual derivó en la caída de los precios. Al recuperar la economía, y con ella la capacidad de compra y, valga decir, de endeudamiento, las exportaciones se reactivaron y los precios volvieron a subir.

En lo que toca a América Latina y a su atávica dependencia de los mercados norteamericanos, la situación no es muy distinta, la diferencia la aporta la intermediación de China, compradora y procesadora de las materias primas latinoamericanas que así se exportan tanto a Norteamérica como al mundo entero.

En este contexto, Latinoamérica va no sólo depende de sus tradicionales compradores directos sino del papel intermediador de China en la elaboración de productos manufactureros e industriales; la vulnerabilidad aumenta $\mathrm{y}$, con ella, el margen de riesgo e incertidumbre frente a unas variables que los países latinoamericanos no controlan; de este modo, si la demanda de nuestros bienes procesados a través de China cae (ya no podemos hablar de nuestros productos puestos que éstos ahora son chinos). la economía latinoamericana se verá amenazada: razón más que de sobra para cuidar nuestra relación con el gigante asiático..

La situación es clara. América Latina necesita que los países consumidores continúen comprando $\mathrm{y}$, de tal suerte, actuando como motores de la economía mundial; no obstante, como nos recuerda Hinds (2011). "Cuando una economía importa más de lo que exporta la diferencia la paga con deuda"; de este modo, estos países podrán seguir comprando mientras sus economías aguanten el creciente endeudamiento; no debe sorprendernos, entonces, que el siguiente nivel de la crisis tanto de los países como de los ciudadanos, venga de mano del crédito y, por tanto, de la capacidad de endeudamiento, pues toda capacidad de endeudamiento tiene su límite como hace poco nos recordó Grecia. 
Por lo anterior i.No será una trampa del sistema financiero internacional dirigir los oios hacia las economías emergentes, orientando hacia ellas la inversión, para recargar sobre éstas la responsabilidad de actuar como nuevos "motores" de la economía mundial? iQuién pagará el costo de ser comprador acumulando más y más deuda? Si América Latina no equilibra su balanza entre lo que compra y lo que vende de seguro caerá en la trampa en la que va caveron los países desarrollados y que hoy en día dirigen sus ojos hacia estos nuevos espacios de sospechosa "oportunidad"...

No obstante, en el actual orden de cosas, antes que para América Latina y los demás países en "vías de desarrollo", la salida para los países desarrollados en crisis, consiste en lograr un equilibrio entre sus exportaciones y sus importaciones con el fin de estabilizar su economía, lo cual podrá convenirles a ellos pero no a los países productores que dependen, por ahora, precisamente, de la salida de sus productos y materias primas, así sea a través de la riesgosa mediación de China.

De este modo, el hecho de que los actuales países motores de la economía para el mundo, en tanto consumidores tradicionales, empiecen a valerse por ellos mismos, es decir, dejen de ser motores para los demás, derivará en una crisis económica para el resto del planeta; la que de hecho ya se ha anticipado a través de las consecuencias que, para el mundo entero, tiene la enorme acumulación de deuda concentrada en los países desarrollados i.De dónde saldrá el dinero si no es de la rotación de la responsabilidad en la actuación como motor de la economía mundial? "Que se endeuden otros" parecen decir a coro los países centrales con la anuencia de los Bancos y de las empresas que mueven el gran capital. Oscuro destino, no sólo para los BRIC, sino para todos aquellos países que caigan en la trampa..

La pregunta que propone Hinds en este punto no puede ser otra: "iPodrán los BRIC convertirse en motores ellos mismos, importando más de lo que exportan?" (Hinds. 2011). La respuesta que compartimos con este autor es que probablemente no, al menos no en la magnitud con la que lo venían haciendo los grandes consumidores.

Con todo, la creación del BRIC es atípica puesto que aún no tiene una causa concreta distinta a la de convertirse en "motor" (i.endeudándose?). No obstante, mientras la encuentra, nos atrevemos a dudar que, en realidad, pueda convertirse este Grupo en un verdadero motor de la economía mundial; lo que sí es cierto es que se ha convertido en una sugerente marca avalada por una presencia mediática considerable, 
lo cual lo hace más un producto de la mercadotecnia que un provecto definido. No obstante, esto no se debe menospreciar, la mercadotecnia posiciona, comercializa y, lo más importante, vende...

El asunto es, entonces, si debemos permitir que sean los Bancos y sus particulares intereses los que integren o agrupen naciones enteras a la luz de dudosos, ambiguos y, muchas veces, ilegítimos indicadores, o si deben ser los Estados-Nación, mientras todavía existan, los que se encarguen de establecer agendas comunes con países vecinos, o no, y así definir con quién, por qué y cómo asociarse en el ámbito de nuevos procesos de integración regional; más aún, definir su idea de región en el marco de las nuevas realidades territoriales del siglo XXI y su innegable imperativo de movilidad.

En este contexto, la regionalización que pudiera dar pie a nuevos procesos de integración transnacional en el marco de una idea ampliada, que no renovada de "ordenamiento territorial" - pues, al fin de cuentas, tanto en la escala de las ciudades como de las mega-regiones económicas mundiales, se trata de lo mismo, de disponer el espacio para el flujo de capital - no necesariamente tendría que pasar por la noción clásica de contigüidad regional (de vecindad fronteriza); de cualquier forma, es posible que el tiempo de integraciones asociacionistas del tipo "Unión Europea" haya dado paso, sin decir que, al menos aún, se hayan agotado, a nuevas formas de organización estratégica del territorio, sin que ello suponga, como ya anotamos, nuevas maneras de entender el ordenamiento del territorio aunque si de lo territorial ya no asociado con una idea fija e inamovible de confinamiento socio-espacial.

De cualquier forma, mientras lleguemos al "mundo sin fronteras" por el que aparentemente aboga la globalización ${ }^{5}$, y del cual ya hemos tenido un avance a través de las consecuencias que ha traído la desregulación de los mercados, quizá sea necesario fortalecer de nuevo la idea de los Estados-Nación, al menos desde la perspectiva que supone el respeto a la

\footnotetext{
${ }^{5}$ Decimos "aparentemente" puesto que la "superación de las fronteras", ya conquistada en buena medida por el mercado, encuentra paradójicamente en ellas su mayor aliado dada la diversidad de oportunidades que uno u otro país oferta al capital trasnacional, las cuales van, desde la disminución o supresión de los impuestos y aranceles, hasta la constitución de paraísos fiscales; para no hablar de la conveniencia al gran capital en general y al inversionista en particular, que los distintos países ofertan en el mercado a través de sus legislaciones en materia tanto ambiental como laboral, o de la corrupción que en muchos países "ablanda" o flexibiliza tales legislaciones.
} 
autodeterminación de los pueblos y a la capacidad de liderazgo que, en el marco de efectivas alianzas estratégicas, uno u otro Estado pueda propiciar, actuando en red y siempre bajo la premisa del respeto, la solidaridad y la integridad no sólo con los demás pueblos sino con el frágil ecosistema que globalmente nos cobija a todos por igual.

De este modo, e independiente del hecho de que cada uno de los países del BRIC tenga aspiraciones de liderazgo, la verdad es que hov en día están más interesados en mantener el estatus que les proporciona la marca de Grupo que en asumir los derroteros que les supondría ser auténticos y ejemplares líderes de la economía y las relaciones internacionales del siglo actual a la luz de un nuevo modelo económico que privilegie y priorice la equidad social, la conciencia ambiental, los derechos humanos, el equilibrio territorial y la justicia social.

Lo que de esta forma nos muestran las agrupaciones regionales transnacionales tipo BRIC es, no solamente la emergencia de un nuevo tipo de región trans-cultural no homogénea compuesta por miembros no colindantes, sino la necesidad de entender la regionalización del siglo XXI a la luz de la creación de coyunturales grupos, ni fijos ni estacionarios dado que sus miembros pueden aumentar o decrecer según las dinámicas de la economía mundial - que en su inmadurez, falta de provecto colectivo y de identificación corporativa no logran constituir una propuesta alternativa al modelo económico vigente sino que, por el contrario, a la luz de los obietivos que con su creación alentaran los Bancos, más bien se limitan a tratar de acomodarse al interior de una insustentable élite ungida por los Bancos para poder sobrevivir, al menos por un tiempo, dentro del mercado.

A fin de cuentas, nada garantiza que la vinculación a uno de estos privilegiados Grupos salve a estos países de la crisis, más bien, por el contrario, de no aprender de las lecciones de la historia y del destino que la misma trazó a los anteriores motores económicos, a lo meior lo que se les viene encima es una trampa del modelo económico en el cual confían y frente al cual, si en verdad quieren sobrevivir y liderar un cambio, deben a todas luces apartarse.

En este sentido, no se puede desconocer la enorme oportunidad que supone la creación de tales Grupos para configurar proyectos colectivos, esquemas de cooperación y sistemas alternativos de inversión capaces de enfrentar los problemas comunes que a todos afectan y que, entre otras cosas, requieren actuar de manera coniunta y coordinada. Es necesario superar las relaciones colonialistas de dependencia construidas a lo largo 
de los últimos siglos para establecer marcos comunes de cooperación y de alianzas horizontales donde los interlocutores se vean de tú a tú.

Qué meior oportunidad que esta para que España, por eiemplo, en el marco de su grave crisis, se acerque a sus ex -colonias para asociarse con ellas en vez de tratar de seguir manteniendo el modelo de subordinación colonial que, de manera obstinada e insistente, se empeña en mantener.

Lo cierto es que la crisis económica que estamos viviendo, de la mano del surgimiento de los nuevos bloques regionales aludidos $\mathrm{y}$ conformados por países de economías emergentes, no necesariamente colindantes, lo que pone de manifiesto es la necesidad de alentar, al interior del modelo económico vigente, un espíritu asociacionista, aunque, evidentemente empresarial y todavía de dudosa naturaleza que, paradóiicamente en el contexto individualista de la competitividad per se que tradicionalmente impuso el capitalismo neoliberal a través de la desregulación de los mercados, abra nuevas posibilidades de inversión, de movilización del capital, de reactivación de las economías y, por supuesto, de crecimiento económico.

En este contexto, es claro que el modelo colonialista de economías de dependencia del tipo explotador-explotado que durante tanto tiempo marcó la relación entre países ricos y pobres ha ido sustituyéndose por el de común dependencia frente a empresas multinacionales y Bancos que, en consecuencia, hoy en día son los encargadas de someter implacablemente a unos y a otros propiciando, cuando no promoviendo, como en el caso de los BRIC, nuevos modelos de asociación, aún no desarrollados.

Lo paradóiico de esta situación, que no deia de ser una oportunidad para la construcción de provectos colectivos, es que han sido, precisamente los Bancos, quienes han promovido y facilitado estos nuevos modelos de asociación propiciando, no sólo la posibilidad de integración de países con economías diversas y en diferentes niveles de proyección, sino la necesidad de hacerlo.

Lo que aquí está pendiente es que los países vinculados a través de los grupos mencionados vean la posibilidad de mejorar sus economías a través de ellos por la vía de la articulación frente a problemas comunes, aunque diferenciados en sus acentos, respecto de la crisis generalizada que a todos afecta aunque, por ahora, de manera desigual.

En el marco de tales grupos y, frente a la crisis señalada, las reacciones individuales histéricas del tipo "sálvese quien pueda", correspondientes con la situación de países desprotegidos o asilados, no 
tienen sentido en el marco de la constitución de alianzas estratégicas concebidas para superarla.

Si bien cuando los Bancos empezaron a pensar - como respuesta a la flagrante crisis en que se encuentra el modelo económico vigente - en incentivar y proponer la creación de los referidos grupos económicos emergentes, o grupos de países con economías emergentes, con el fin de reactivar el gran capital, a lo último que aspirarían sería a que éstos se convirtieran en los promotores de un nuevo orden mundial basado en el cuestionamiento radical del actual modelo económico, sino que, por el contrario, fuesen precisamente estos grupos quienes lideracen el proceso de reciclaie y reactivación del actual modelo económico, lo cierto es que han sido precisamente los Bancos quienes han propiciado tal posibilidad; pero cuidado, los Bancos no actúan de manera ingenua y lo último que buscarían sería que les saliese "el tiro por la culata", primero intrigarán, conspirarán, endeudarán y harán todo lo posible por mantener la particular estructura de orden que han impuesto subordinando y reconfigurando el propio orden del Estado, de ahí la imperiosa necesidad de fortalecer éste a través de la articulación entre modelo económico, modelo de gobierno y modelo de ordenación y planeamiento del territorio.

\section{El papel de los grupos económicos emergentes en la reconfiguración de lo territorial: retos para la planeación urbano- regional a la luz de un nuevo proyecto de ordenamiento territorial capaz de articular modelo de ciudad con modelo de gobierno}

Si hasta aquí hemos planteado la manera como los bancos y las grandes multinacionales financieras, a través de los grupos económicos emergentes, juegan un papel preponderante en la reconfiguración, no sólo de lo regional transnacional sino de lo territorial en cuanto tal, ahora queremos señalar los retos que, a nuestra manera de ver, se derivan de aquí para la ciudad, particularmente latinoamericana, en lo que respecta a su posibilidad de aportar en la transformación del modelo económico vigente a partir de una estrecha articulación entre un modelo de ciudad concertado e incluyente y un modelo de gobierno democrático y participativo que, en consecuencia, se ocupe de dotar de un nuevo sentido, no sólo a lo territorial, sino a la planeación y al ordenamiento mismo de la ciudad, para lo cual consideramos esencial la generación de equilibrios territoriales por la vía de: 
- Esclarecer la importancia de tal articulación para la definición y realización de un modelo dinámico de sociedad

- Entender y asumir, como sociedad, las consecuencias que, en sus múltiples dimensiones, supone la elección de uno u otro modelo de ciudad, entendido éste como una forma de organización de la sociedad sobre el espacio y, por lo mismo, como un modo implícito de administrarlo y gobernarlo

- Definir la manera como, entre otros posibles, deben articularse modelos de ciudad compactos, dispersos, fragmentarios o difusos, con modelos de gobierno centralizados o descentralizados, pluralistas, participativos, comunitaritas y democráticos

- Establecer con los diferentes estamentos de la sociedad una ruta de actuación concertada que permita el despliegue, desarrollo y posicionamiento de la ciudad como escenario común compartido

- Incentivar la participación deliberativa, la pedagogía social, el compromiso multi-actoral, el control social y la auto-regulación ciudadana

- Minimizar los umbrales de riesgo de la sociedad a partir de la generación de pactos multi-estamentarios incluyentes v participativos

- Promover la búsqueda de un modelo de ciudad sustentable por la vía de la apropiación ciudadana

- Promover la corresponsabilidad social involucrando a la ciudadanía en la toma de decisiones

- Garantizar la obtención de una gobernabilidad democrática y el efectivo derecho a la ciudad para todos y todas sus habitantes

- Procurar la satisfacción integral de las necesidades básicas insatisfechas de la población y elevar sus índices de calidad de vida

- Enfrentar la exclusión y la injusticia social, la segregación socioespacial y los desequilibrios territoriales

- Meiorar la productividad y la competitividad urbanas en el marco de un claro esquema de iusta distribución de los excedentes

- Suplantar la idea del combate a la pobreza por la de combate a la exclusión, la estigmatización y la inequidad

Desde aquí, consideramos fundamental:

- Entender que no existe un modelo de gobierno ideal para un determinado modelo de ciudad sino que tanto uno como otro deben construirse colectiva y coordinadamente en atención al horizonte de sentido que cada sociedad establezca 
- Concebir la política pública de tal suerte que se garantice, al interior de las distintas fuerzas vivas de la sociedad, la construcción colectiva de un imaginario de ciudad común concertado con un horizonte de sentido viable, factible y cotejable a lo largo del tiempo a través de un sistema de indicadores claramente estructurado en función de etapas y acciones estratégicas acordadas

- Asumir la gestión de la ciudad como un proceso integral de gestión urbana que atienda todas sus dimensiones y no, simplemente, los temas de equipamientos, suelo o servicios.

- Establecer como principio de política pública en la acción sobre el territorio la participación multi-actoral $\mathrm{y}$ multi-estamental en corresponsabilidad así como la articulación inter-institucional

- Anteponer a la idea neoliberal de negocio inmobiliario, la de operación estratégica para la ciudad

- Definir y aplicar un claro y transparente esquema de distribución de cargas y beneficios así como de administración y aprovechamiento público de las plusvalías

- Adoptar diferentes esquemas de propiedad del suelo y de distribución equitativa de su renta

- Incorporar a la noción de gestión del suelo, la del riesgo, el conflicto y la convivencia

- Exigir, a la hora de definir la política pública y llevar a cabo correspondientes actuaciones y proyectos, la participación ciudadana en corresponsabilidad social

- Construir colectivamente la norma urbana y promover, dentro de ella, la auto-regulación ciudadana y el control social

- Aceptar la idea de que en la ciudad existen múltiples ideas de ciudadanía que es necesario convocar y alentar a la hora de definir la política pública

- Propiciar y garantizar la concurrencia de recursos y esfuerzos públicos y privados a la hora de definir y llevar a cabo actuaciones sobre el territorio

- Instaurar en los procesos de planeación y ejecución de acciones y provectos una mirada trans-sectorial que responda a la naturaleza compleia e imbricada de los problemas urbanos

- Diseñar, de manera concertada con las fuerzas vivas de la sociedad, una eficiente arquitectura de la participación en el marco de un consecuente sistema de participación amparado en una correspondiente ley orgánica

- Constituir y/o fortalecer diferentes instancias de participación deliberativa y no simplemente consultiva 
- Articular los temas de la planificación y de la administración de la ciudad dentro de un esquema claramente territorializado aunque coordinado por eficientes y competentes instancias rectoras

- Incorporar en la lógica de la planificación urbana y del ordenamiento territorial las distintas formas de hacer ciudad, reconociendo dentro de ellas la legitimidad de los desarrollos espontáneos

- Dotar la articulación mencionada de una dimensión cultural dentro de la cual se resalte el valor patrimonial de la práctica cultural y del paisaje urbano

- Incorporar de manera efectiva el valor sustantivo de la cultura urbana y de su correlato patrimonial a la hora de adoptar uno u otro modelo de ciudad en el marco de un consecuente modelo de gobierno

- Llenar de contenido la entelequia abstracta del contrato social mediante la formulación y realización de pactos concretos por la vida, el medio ambiente, la movilidad, la seguridad, el espacio público, etcétera

- Explorar sistemas alternativos y colectivos de propiedad

EL GRUPO BRIC Y EL "EFECTO ROQUEFORT": UNA APROXIMACIÓN A LA NOCIÓN DE REGIÓN-EMERGENTE EN EL CONTEXTO DE LA GLOBALIZACIÓN

Palavras-chave: Regiões emergentes, Globalização, Ordenamento Territorial, Modelo Econômico, Equilíbrio Territorial.

Resumo: As imensas demandas que a economia política da globalização impôs aos distintos países e territórios para se posicionarem no mercado a qualquer custo se comportou como um imperativo que começa a reger os distintos entornos humanos. Neste contexto, tais entornos devem adequarse através de políticas correspondentes de planejamento e ordenamento do território que reconfiguram totalmente a ideia tradicional do regional. Surge assim a ideia de "territórios emergentes" e a necessidade de agrupálos para torná-los mais sólidos, confiáveis, competitivos e atrativos, situação que tem a ver não apenas com a conformação de agrupamentos ou de associações de municipios ou ciudades e mesmo de países inteiros, tal como ilustra o caso do Grupo BRIC que abordamos neste trabalho. 
THE BRIC GROUP AND THE "ROCKEFORT EFFECT": AN APPROXIMATION TO THE NOTION OF EMERGING-REGION IN GLOBALIZATION CONTEXT: impacts in the notion of territorial ordering

Kevwords: Emerging regions, globalization, territorial ordering, economical model, territorial balance

Abstract: The enormous demands that the political economy of globalization has imposed on different countries and territories get in all positions and standing in all markets at any cost, this has an imperative action and huge effect in to human environments. In this context, such environments must adapt through an appropriate planning policies and territorial

development using strategic plans to reconfigure any traditional idea of a regional. Thus, the idea of "emerging territories" and the grouping need to make them more solid, reliable, competitive and attractive, this issue has to build groups and associations forms, and also getting involve with municipalities, cities, and even entire countries has been illustrated the BRIC groupal ready, which will be discussed in the final part of this work.

\section{BIBLIOGRAFÍA}

BBVA (febrero 14, 2011), BBVA EAGLEs, Madrid, BBVA Research.

Disponible en:

http://www.bbvaresearch.com/KETD/ketd/esp/nav/eagles.jsp

COOPER, T. Foster, M. y Purdy. M (February 2010). Creating a winning geographic strategy. Dublin: Accenture.

GOLDMAN, S. (31 January 2011), "It Is Time to Re-define Emerging Markets”. New York.

Asset Management. The Economist (September 18th, 2008), "Ins and Outs. Acronyms BRIC out all over". Disponible en http://www.economist. com/node/12080703?story_id=12080703

. (1st December 2005), "How Solid Are the BRICs?". New York . (1st October 2003), "Dreaming with BRICs: The Path to 2050", New York, Goldman Sachs, Global Economics Paper: No. 99. 
. (30th November 2001), "Building Better Global Economic BRICs", New York, Goldmam Sachs, Global Economics Paper No. 66. Hinds, M. (2011) "Los motores de la economía mundial", Editorial en El Diario de Hoy. Jueves 4 de Agosto de 2011. San Salvador.

Magnus, G. (2011), Uprising, West Sussex, Londres: John Wiley \& Sons Ltd.

POTTER, E. (2009). Branding Canada. Montreal \& Kingston, McGill.Queen's Montreal: University Pressl.

PESEK, W. (February 21, 2011), “Goldman's picks can't beat '7\% Club' on sexiness", en The Financial Express, disponible en http://www.financialexpress.com/news/goldmans-picks-cantbeat7-club-on-sexiness/752565/3

PRECEDO, A. (2004). Nuevas realidades territoriales para el siglo XXI. Desarrollo local, identidad territorial y ciudad difusa. Madrid: Ed. Síntesis.

PURDY, M. Robbinson, M. y Nunes, P. (June 2009). Adapting to the multi-polar world. The new globalization playbook. Dublin: Accenture.

RIGAUD, P. (2010), Les BRIC. Brésil, Russie, Inde, Chine, puissances émergentes. Paris: Bréal.

ROSAS. M. C. (2011) Revista Etcétera Numero del 08-08-2011. México D.F.

STANDARD CHARTERED (25 May 2010). Prospectus. Londres: Standard Chartered.

YORY, C. M. (2007). "Desarrollo territorial integrado, ciudad difusa y nuevas ruralidades: Consideraciones propositivas para fortalecer el tema de la ciudad-región en el diseño y revisión de los Planes de Ordenamiento Territorial"; en Revista ACTA GEOGRÁFICA N ${ }^{\circ} 1$. Boa Vista (Roraima): Universidad Federal de Roraima-UFRR. Instituto de Geociencias.

ZAKARIA, F. (2009). El mundo después de USA. Madrid: Espasa 